\title{
Precipitation sequence in niobium-alloyed ferritic stainless steel
}

\author{
Nobuhiro Fujita ${ }^{1}$, H K D H Bhadeshia ${ }^{2}$ and Masao Kikuchi ${ }^{1}$ \\ ${ }^{1}$ Steel Research Laboratories, Nippon Steel Corporation, 20-1 Shintomi Futtsu, 293-8511, Japan \\ 2 Department of Materials Science and Metallurgy, University of Cambridge, Pembroke Street, \\ Cambridge CB2 3QZ, UK
}

Received 11 August 2003

Published 16 February 2004

Online at stacks.iop.org/MSMSE/12/273 (DOI: 10.1088/0965-0393/12/2/008)

\begin{abstract}
Niobium is an important alloying element in the design of heat-resistant ferritic stainless steels for automotive exhaust systems. When in solid solution, it improves both the high temperature strength and the resistance to thermal fatigue. However, it also forms several kinds of precipitates during service. These reactions have been modelled, taking into account the multicomponent nature of the diffusion process and allowing for capillarity effects. It has been possible to estimate not only the volume fractions but also the particle sizes for $\mathrm{Fe}_{2} \mathrm{Nb}$ (Laves phase) and $\mathrm{Fe}_{3} \mathrm{Nb}_{3} \mathrm{C}\left(\mathrm{M}_{6} \mathrm{C}\right)$ carbide in a $19 \mathrm{Cr}-0.8 \mathrm{Nb}$ steel, with good agreement against experimental data.
\end{abstract}

\section{Introduction}

The fuel economy of internal combustion engines and the cleanliness of the associated emissions can be improved by increasing the temperature of the exhaust gas, which currently can be in excess of $900^{\circ} \mathrm{C}$. Materials are, therefore, required to resist heat and thermal fatigue, both of which are important properties for the exhaust manifold of cars.

Niobium is an important solute in the design of heat-resistant stainless steels for automotive exhaust systems [1-5]. When in solid solution, it improves both the high temperature strength and the resistance to thermal fatigue [5]. However, it also forms a variety of precipitates, including $\mathrm{Nb}(\mathrm{C}, \mathrm{N})$ (carbonitride), $\mathrm{Fe}_{2} \mathrm{Nb}$ (Laves phase) and $\mathrm{Fe}_{3} \mathrm{Nb}_{3} \mathrm{C}\left(\mathrm{M}_{6} \mathrm{C}\right.$ carbide) during service. It is important in the development process to understand the kinetics of the simultaneous precipitation and coarsening reactions. There exists a theory for NbC formation in the austenite phase of low-alloy steels [6-10] and for precipitation sequences in ferritic, heat-resistant steels [11-15]. However, there has not been much work of this kind on ferritic stainless steels [16] because of their complexity and due to a lack of appropriate thermodynamic data. It is the purpose of this paper to model the evolution of precipitates in niobium-alloyed ferritic stainless-steels, taking into account the multicomponent nature of diffusion, of capillarity effects and of interactions between different kinds of precipitates, by using a simultaneous transformation framework [13, 14]. 
Table 1. Chemical composition (wt $\%$ ) of the ferritic stainless steel studied here.

\begin{tabular}{lllllll}
\hline Steels & $\mathrm{C}$ & $\mathrm{Si}$ & $\mathrm{Mn}$ & $\mathrm{Cr}$ & $\mathrm{Nb}$ & $\mathrm{N}$ \\
\hline $19 \mathrm{Cr}-0.8 \mathrm{Nb}$ & 0.014 & 0.2 & 0.3 & 19.6 & 0.78 & 0.016 \\
\hline
\end{tabular}

Table 2. X-ray and chemical analyses of extraction residues from $19 \mathrm{Cr}-0.8 \mathrm{Nb}$ wt $\%$ steel. VW, W, $\mathrm{S}$ and VS stand for very weak, weak, strong and very strong $\mathrm{X}$-ray intensities, respectively.

\begin{tabular}{|c|c|c|c|c|c|c|c|c|}
\hline \multicolumn{2}{|c|}{ Ageing conditions } & \multicolumn{3}{|c|}{ Precipitates detected } & \multicolumn{4}{|c|}{$\begin{array}{l}\text { Each element in } \\
\text { precipitates (mass\%) }\end{array}$} \\
\hline $\begin{array}{l}\text { Ageing } \\
\text { temperature }\left({ }^{\circ} \mathrm{C}\right)\end{array}$ & $\begin{array}{l}\text { Ageing } \\
\text { time (h) }\end{array}$ & $\mathrm{Nb}(\mathrm{C}, \mathrm{N})$ & $\mathrm{M}_{6} \mathrm{C}: \mathrm{Fe}_{3} \mathrm{Nb}_{3} \mathrm{C}$ & $\mathrm{Fe}_{2} \mathrm{M}: \mathrm{Fe}_{2} \mathrm{Nb}$ & $\mathrm{Nb}$ & $\mathrm{Fe}$ & $\mathrm{Cr}$ & $\mathrm{N}$ \\
\hline \multirow[t]{3}{*}{$\begin{array}{l}\text { As annealed } \\
\text { at } 1000^{\circ} \mathrm{C}\end{array}$} & & $S$ & VS & $\mathrm{W}$ & 0.204 & 0.214 & 0.042 & 0.014 \\
\hline & 1 & VS & VS & VS & 0.407 & 0.326 & 0.051 & 0.015 \\
\hline & 8 & S & VS & $\mathrm{W}$ & 0.460 & 0.298 & 0.048 & 0.016 \\
\hline \multirow[t]{3}{*}{950} & 20 & $S$ & VS & $\mathrm{W}$ & 0.458 & 0.289 & 0.047 & 0.016 \\
\hline & 50 & $\mathrm{~S}$ & VS & VW & 0.432 & 0.247 & 0.044 & 0.013 \\
\hline & 100 & VW & VS & - & 0.443 & 0.234 & 0.041 & 0.014 \\
\hline 1000 & 20 & $\mathrm{~W}$ & VS & - & 0.362 & 0.171 & 0.037 & 0.015 \\
\hline
\end{tabular}

\section{Experimental procedure}

Table 1 shows the chemical composition of niobium-alloyed ferritic stainless steel, with a nominal composition $19 \mathrm{Cr}-0.8 \mathrm{Nb}$ wt $\%$. The alloy was vacuum-melted as a $10 \mathrm{~kg}$ ingot which was then heated to $1250^{\circ} \mathrm{C}$ for $30 \mathrm{~min}$ in an argon atmosphere, hot-rolled to a $12 \mathrm{~mm}$ thickness plate and air-cooled from a finishing temperature of about $900^{\circ} \mathrm{C}$. The plate was annealed at $1000^{\circ} \mathrm{C}$ for $10 \mathrm{~min}$ and then quenched in water. Samples were machined for a variety of isothermal heat-treatments at $950^{\circ} \mathrm{C}$ and $1000^{\circ} \mathrm{C}$ for up to $500 \mathrm{~h}$. Electrolytically extracted residues were analysed using $\mathrm{x}$-ray diffraction to identify the precipitates.

The microstructures were characterized mainly using carbon extraction replicas examined using transmission electron microscopy (TEM), electron diffraction and energy dispersive x-ray analysis (EDS). This also helped characterize particle sizes. Replicas were made by vacuum evaporating carbon films onto the sample surface. The carbon replicas were then collected on $3 \mathrm{~mm}$ diameter copper grids. An etching solution of $10 \mathrm{~g} \mathrm{l}^{-1}$ tetramethylammonium chloride, $10 \mathrm{vol} \%$ acetylacetone in methanol at a potential between 0 and $200 \mathrm{mV}$ proved satisfactory during the extraction process. Because several types of precipitates are expected in aged steels, replica specimens make it easy to identify and size each phase. Thin-foil specimens can also be used but replicas are able to cover a broad size range from $10 \mathrm{~nm}$ to $1 \mu \mathrm{m}$.

$\mathrm{M}_{6} \mathrm{C}$ type carbide may be an equilibrium phase $[16,18]$; it was characterized mostly during its coarsening stage. An effective radius $r$ was determined assuming that the area of each particle is equal to that of a circle of radius of $r$. At least 100 particles were measured in each experiment.

\section{Experimental results}

Table 2 shows the results of chemical and $\mathrm{x}$-ray analyses of extracted residues from the samples aged at $950^{\circ} \mathrm{C}$ and $1000^{\circ} \mathrm{C}$ for a $19 \mathrm{Cr}-0.8 \mathrm{Nb}$ wt $\%$ steel. $\mathrm{Nb}(\mathrm{C}, \mathrm{N})$, Laves phase $\left(\mathrm{Fe}_{2} \mathrm{Nb}\right)$ and 

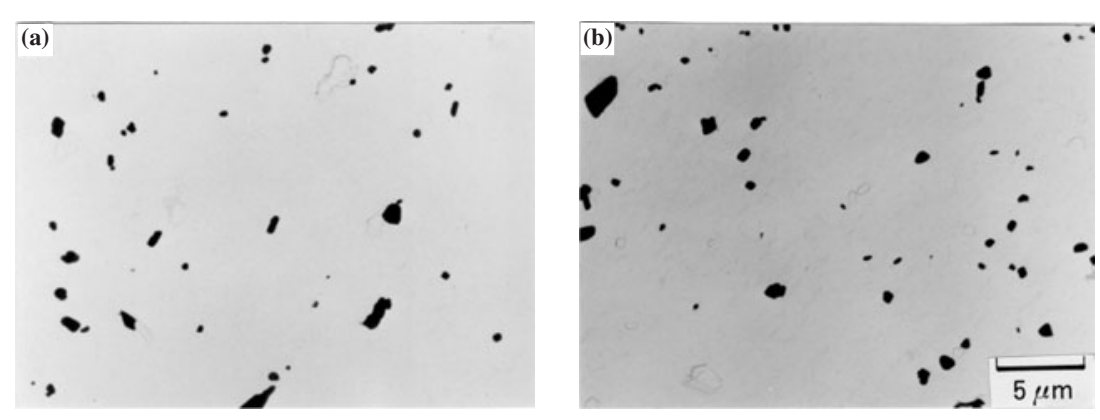

Figure 1. Transmission electron micrographs for a $19 \mathrm{Cr}-0.8 \mathrm{Nb}$ wt $\%$ steel aged at $950^{\circ} \mathrm{C}$ for $(a) 20 \mathrm{~h}$ and $(b) 100 \mathrm{~h}$.
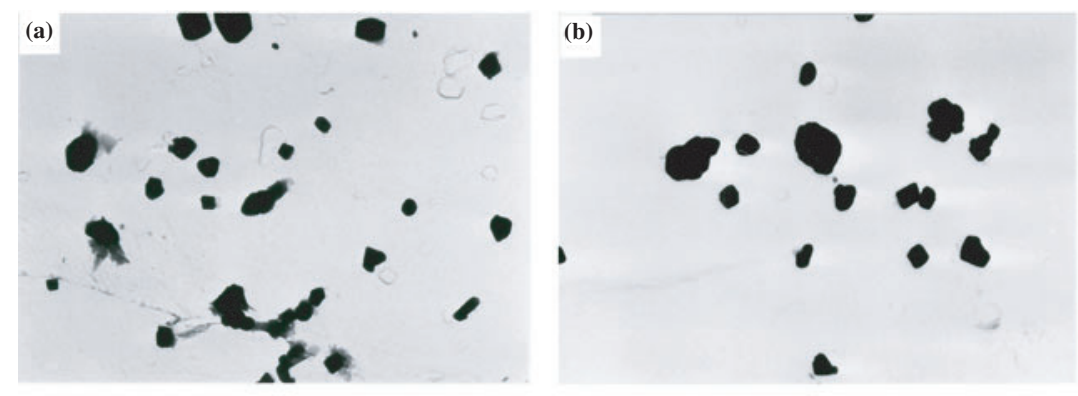

(c)

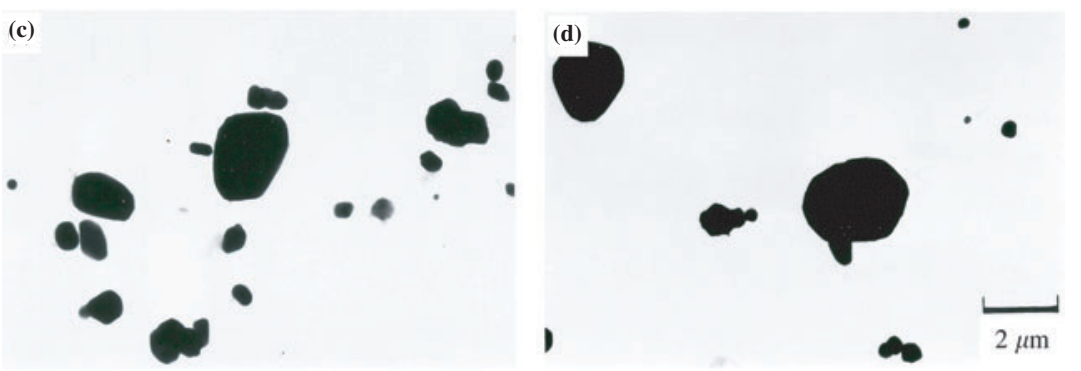

Figure 2. Extraction replica transmission electron micrographs of a $19 \mathrm{Cr}-0.8 \mathrm{Nb}$ wt $\%$ steel aged at $1000^{\circ} \mathrm{C}$ for $(a) 1 \mathrm{~h},(b) 10 \mathrm{~h},(c) 100 \mathrm{~h}$ and $(d) 500 \mathrm{~h}$.

$\mathrm{Fe}_{3} \mathrm{Nb}_{3} \mathrm{C}$ carbide were detected during the early stages of ageing. On continued ageing, the $\mathrm{x}$-ray intensity due to $\mathrm{Nb}(\mathrm{C}, \mathrm{N})$ and Laves phase decreased and that due to $\mathrm{Fe}_{3} \mathrm{Nb}_{3} \mathrm{C}$ increased. According to a chemical analysis of the extracted residues, most of the nitrogen precipitated, probably as $\mathrm{NbN}$, implying that $\mathrm{NbC}$ dissolves and $\mathrm{NbN}$ remains. The atomic ratio of $\mathrm{Fe}$ to $\mathrm{Nb}$ in the extracted residue approached unity as the ageing time increased. This indicates that the $\mathrm{NbC}$ and Laves phases, which contain more iron than required by stoichiometry in $\mathrm{Fe}_{3} \mathrm{Nb}_{3} \mathrm{C}$, dissolve to give way to $\mathrm{Fe}_{3} \mathrm{Nb}_{3} \mathrm{C}$. It appears, therefore, that the equilibrium phases in the $19 \mathrm{Cr}-0.8 \mathrm{Nb}$ wt $\%$ steel are $\mathrm{NbN}$ and $\mathrm{Fe}_{3} \mathrm{Nb}_{3} \mathrm{C}$ :

$$
\alpha \rightarrow \alpha+\mathrm{Nb}(\mathrm{C}, \mathrm{N})+\mathrm{Fe}_{2} \mathrm{Nb}+\mathrm{Fe}_{3} \mathrm{Nb}_{3} \mathrm{C} \rightarrow \alpha+\mathrm{NbN}+\mathrm{Fe}_{3} \mathrm{Nb}_{3} \mathrm{C}
$$

where $\alpha$ represents ferrite. Figure 1, representing specimens aged at $950^{\circ} \mathrm{C}$ for 20 and $100 \mathrm{~h}$, shows that the precipitates are more spherical than plate or needle-shaped. Figure 2 shows transmission electron micrographs for particle coarsening as a function of ageing time. Almost 


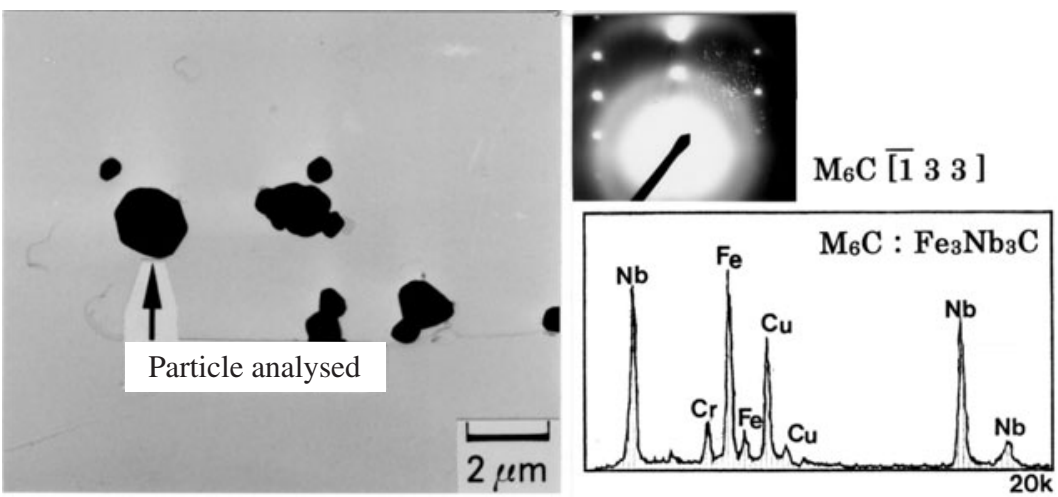

Figure 3. Transmission electron micrographs and corresponding electron diffraction and EDS data for a $19 \mathrm{Cr}-0.8 \mathrm{Nb}$ wt $\%$ steel aged at $1000^{\circ} \mathrm{C}$ for $100 \mathrm{~h}$.

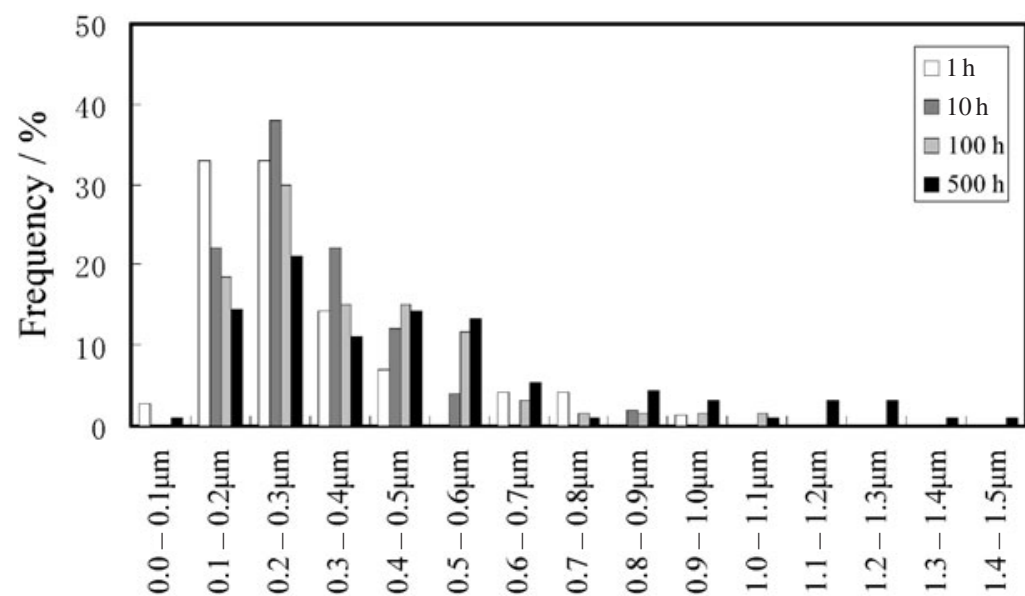

Particle size range

Figure 4. Changes in the particle size distribution with ageing time at $1000^{\circ} \mathrm{C}$ for a $19 \mathrm{Cr}-0.8 \mathrm{Nb}$ wt $\%$ steel.

all of the particles following ageing at $1000^{\circ} \mathrm{C}$ for $100 \mathrm{~h}$ were identified to be $\mathrm{Fe}_{3} \mathrm{Nb}_{3} \mathrm{C}$ (figure 3), the size distribution changing due to coarsening (figure 4).

\section{Model}

\subsection{Nucleation}

Nucleation is assumed to occur at a constant rate in the absence of soft-impingement; this is difficult to justify experimentally because of the variety of precipitation reactions that occur simultaneously. Classical nucleation theory is used to estimate the nucleation rate $I$ for each precipitate. There are several formulae for the rate $I$ [19-22]. For simplicity and taking into account the consumption of nucleation-sites with the term $\left(1-V^{\beta} / V^{\alpha \beta}\right)[10]$, the rate $I$ is 


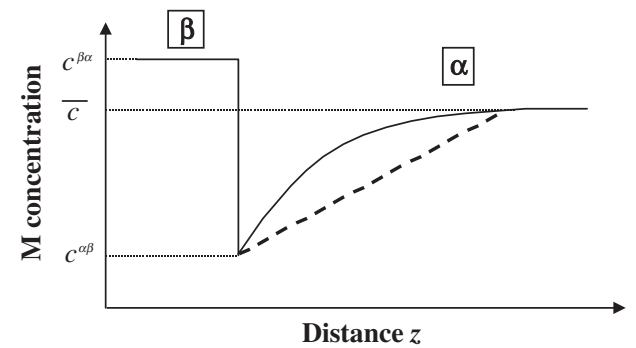

Figure 5. An illustration of the solute concentration profile during diffusion-controlled precipitation of $\beta$ from $\alpha . c^{\alpha \beta}$ and $c^{\beta \alpha}$ are concentrations at the interface $\alpha / \beta$ in the matrix $\alpha$ and the precipitate $\beta$, respectively.

written as

$$
\begin{aligned}
& I=\left(1-\frac{V^{\beta}}{V^{\alpha \beta}}\right) N_{0} \frac{k T}{h} \exp \left(-\frac{G^{*}+Q^{*}}{R T}\right) \\
& G^{*}=\frac{16 \pi \sigma^{3}}{3 \Delta G_{\mathrm{V}}^{2}}
\end{aligned}
$$

where $V^{\beta}$ and $V^{\alpha \beta}$ are instantaneous and equilibrium fractions of the alloy carbide, respectively, $N_{0}$ is the initial number density of nucleation sites, $h$ and $k$ are the Planck and Boltzmann constants, respectively, $Q^{*}$ is the activation energy for the transfer of atoms across the nucleus/matrix interface, assumed to be that for volume diffusion [19], $T$ the absolute temperature, $\Delta G_{\mathrm{V}}$ the chemical free energy change per unit volume, $\sigma$ the energy per unit area of the precipitate-matrix interface and $N_{0}$ and $\sigma$ are in this paper, fitting parameters.

\subsection{Growth}

A reasonable approximation for isothermal diffusion-controlled growth is that the compositions of the phases in contact at the interface are locally in equilibrium. It follows that for a binary alloy these compositions are given by a tie-line of the equilibrium phase diagram. For a binary system, the tie-line is unique and passes through $\bar{c}$ which is the average concentration of solute in the alloy. The concentration profile that develops during the precipitation of a solute-rich phase such as a carbide, is illustrated in figure 5. $c^{\alpha \beta}$ is the concentration of solute in ferrite $(\alpha)$ which is in equilibrium with the carbide $(\beta)$ and $c^{\beta \alpha}$ is the corresponding concentration in $\beta$ which is in equilibrium with $\alpha$. For local equilibrium to be maintained, the rate at which the solute is partitioned into the carbide must equal that at which it arrives at the interface by diffusion, giving the conservation condition

$$
v\left(c^{\beta \alpha}-c^{\alpha \beta}\right)=-\left.D \frac{\partial c}{\partial z}\right|_{z=z^{*}}
$$

where $v$ is the velocity of the interface, $z$ a co-ordinate normal to the interface, $z^{*}$ the position of the interface and $D$ is the diffusion coefficient of the solute in $\alpha$. The concentration gradient is evaluated at the position of the interface, $z=z^{*}$. For a ternary system like Fe-M-C, the tie-line will not in general pass through $\bar{c}$ because it is necessary to simultaneously satisfy two conservation equations at the interface, one each for the substitutional element $\mathrm{M}$ and carbon, which diffuse at vastly different rates [23-25].

$$
\begin{aligned}
& v\left(c_{\mathrm{M}}^{\beta \alpha}-c_{\mathrm{M}}^{\alpha \beta}\right)=-D_{\mathrm{M}} \nabla c_{\mathrm{M}} \\
& v\left(c_{\mathrm{C}}^{\beta \alpha}-c_{\mathrm{C}}^{\alpha \beta}\right)=-D_{\mathrm{C}} \nabla c_{\mathrm{C}}
\end{aligned}
$$




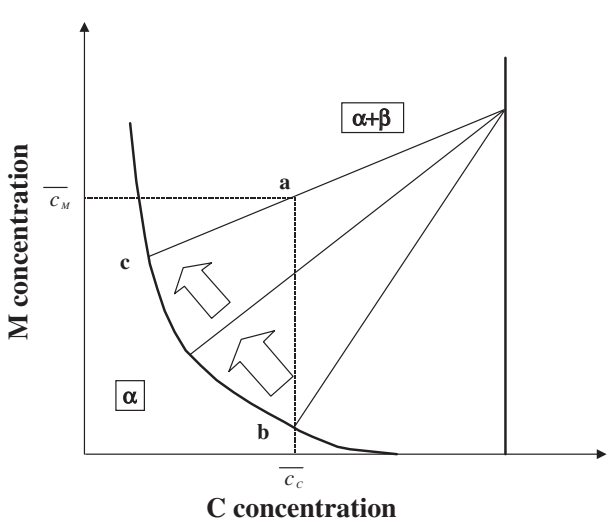

Figure 6. An illustration of an isothermal section through the $\mathrm{Fe}-\mathrm{M}-\mathrm{C}$ phase diagram, showing the precipitate $(\beta) /$ ferrite $(\alpha)$ phase boundaries. The alloy composition is plotted as point $\boldsymbol{a}$.

In this context, the cross-diffusion effect is neglected because of the small dependence of the flux of carbon on the gradient of niobium.

According to the phase rule, there is an additional degree of freedom in a ternary alloy, making it possible to select a tie-line from the two phase $\alpha+\beta$ field, which is able to satisfy both these equations in spite of the fact that $D_{\mathrm{C}} \gg D_{\mathrm{Nb}}$, whilst at the same time maintaining local equilibrium [23-25].

There are two ways in which this can happen [23-25]. The first is for the system to choose a tie-line that greatly increases the gradient of niobium to compensate for its low diffusivity. This would require the carbide to have virtually the same niobium concentration as the matrix with very little partitioning of $\mathrm{Nb}$, but with a steep concentration spike at the interface in order to maintain local equilibrium. This is only possible at large driving forces and hence is not applicable to this work.

The relevant alternative is to select a tie-line which reduces the gradient of carbon to such an extent that the flux of carbon is reduced to a level consistent with that of niobium. Referring to figure 6 , the intersection of the vertical line with the $\alpha /(\alpha+\beta)$ phase field defines completely the tie-line which fixes the interface compositions in a manner which satisfies the conservation conditions because the large diffusion coefficient of carbon is compensated for by the small concentration gradient of carbon [23-25]. This assumes that the far-field concentration $\bar{c}$ does not change during transformation, i.e. there is no 'soft-impingement' of the diffusion fields of different particles. However, soft-impingement is inevitable for the later stages of transformation, in which case the tie-line controlling interface compositions must change to continue to satisfy the conservation conditions. The locus of the matrix composition due to solute depletion during precipitation is along the direction $\boldsymbol{a} \rightarrow \boldsymbol{c}$ (figure 6). The change in the matrix composition also leads to a different choice of tie-line, the locus of $c^{\alpha \beta}$ being along $\boldsymbol{b} \rightarrow \boldsymbol{c}$ (figure 6). This tie-line shifting continues until the reaction stops when the tie-line intersects the average composition $\boldsymbol{a}$ and $c^{\alpha \beta}=\boldsymbol{c}$.

The mean field approximation is used to calculate changes in $\bar{c}$ as precipitation progresses. The instantaneous value of the matrix compositions, $\bar{c}^{\prime}$, is given by

$$
\bar{c}^{\prime}=\frac{\bar{c}-\sum_{i=1}^{n} V_{i}^{\prime} c^{i \alpha}}{1-\sum_{i=1}^{n} V_{i}^{\prime}}
$$

where $V_{i}^{\prime}$ is the volume fraction at any instant for the $i$ th phase and $c^{i \alpha}$ is the equilibrium concentration in $\alpha$ with the $i$ th phase. Once the interface compositions are defined as described 
(a)

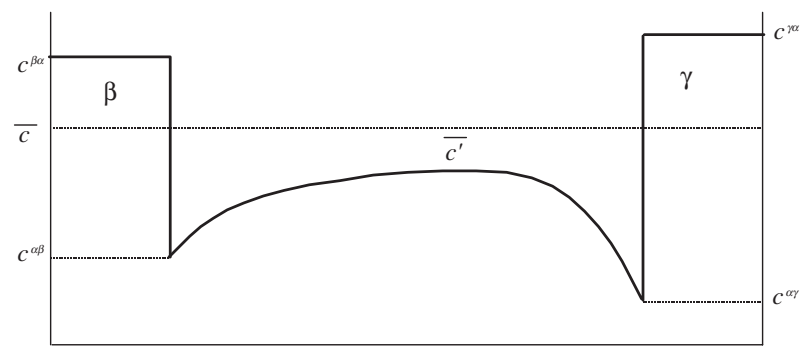

(b)

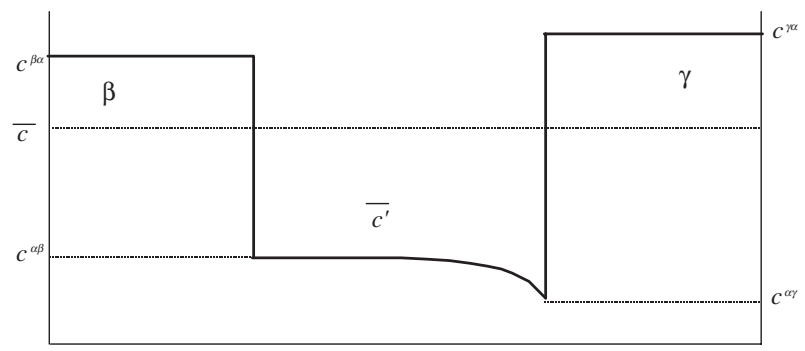

Distance

Figure 7. Distribution of solute when $(a)$ both $\beta$ and $\gamma$ are precipitating, and $(b)$ where the precipitation of $\beta$ has been completed. Note that $\bar{c}^{\prime}$ is the solute concentration in the matrix $\alpha$.

earlier, established theory for diffusion-controlled growth can be applied to estimate the spherical particle radius $r$ as a function of time [22,26]:

$$
z=\alpha_{3} \sqrt{D t} \quad \text { with } \alpha_{3} \approx \sqrt{2 \frac{\bar{c}-c^{\alpha \beta}}{c^{\beta \alpha}-\bar{c}}}
$$

The driving force for nucleation must also be affected by soft-impingement. To deal with this, an extent of reaction parameter $\Phi_{i}$ is defined as follows:

$$
\Phi_{i}=\frac{V_{i}^{\prime}}{V^{i \alpha}}
$$

where $V^{i \alpha}$ is the maximum fraction of the $i$ th phase. The function $\Phi_{i}$ ranges from 0 to 1 and represents the fraction of excess solute remaining in the matrix relative to the equilibrium composition of the precipitate. It is assumed that the driving force for precipitation $\left(\Delta G_{\mathrm{V}}\right.$ in equation (2)) is related linearly to $\Phi_{i}$ :

$$
\Delta G_{\mathrm{V}_{i}}=\left(1-\Phi_{i}\right) \Delta G_{\mathrm{V}_{0 i}}
$$

where $\Delta G_{\mathrm{V}_{i}}$ and $\Delta G_{\mathrm{V}_{0 i}}$ are the driving forces for precipitation at an arbitrary instant and at $t=0$, respectively.

\subsection{Dissolution of the metastable phase}

As mentioned in the section on soft-impingement, the mean solute concentration decreases as the reaction proceeds. Schematic composition profiles are shown in figure 7 for $(a)$ at a time when both the metastable phase $\beta$ and the equilibrium phase $\gamma$ are precipitating in matrix $\alpha$ and then $(b)$ when the solute concentration in the matrix reaches the equilibrium with $\beta$; precipitation of $\beta$ has been completed and as $\gamma$ precipitates further, removing solute, $\beta$ will start to dissolve. 


\subsection{Capillarity}

The state of equilibrium between two phases changes with the curvature of the interface separating them according to the well-established capillarity effect, which scales with the interfacial energy [22]. The free energy of a carbide phase varies relatively sharply with deviations from the stoichiometric composition so it can be assumed that the carbide composition is insensitive to the curvature. However, the equilibrium composition of the matrix changes as follows [22]:

$$
c_{r, \mathrm{M}}^{\alpha \beta}=\left(1+\frac{\sigma}{k T} \frac{v^{\beta}}{r} \frac{1-c_{\mathrm{M}}^{\alpha \beta}}{c_{\mathrm{M}}^{\beta \alpha}-c_{\mathrm{M}}^{\beta \alpha}}\right) c_{\mathrm{M}}^{\alpha \beta}
$$

where $c_{r}^{\alpha \beta}$ is the solute concentration in $\alpha$ which is in equilibrium with a spherical particle of $\beta$ and $r$ is the radius of curvature, which in this case also defines the particle size. The term $c^{\alpha \beta}=c_{r}^{\alpha \beta}$ when $r=\infty$. The modified composition $c_{r}^{\alpha \beta}$ is, therefore, easy to estimate for each particle. For a ternary alloy, capillarity is approximated by calculating the $\alpha /(\alpha+\beta)$ phase boundary on an isothermal section of the phase diagram, as a function of $r$, using equation (9). The growth velocity can then be calculated using the curvature-modified phase boundary. Particles that are smaller than the size of a critical nucleus obviously cannot grow. Nucleation occurs by random fluctuations so that the growth part in the computational scheme must start beyond the nucleation stage. Particles nucleate at different times during the course of the reaction, giving rise to a distribution of sizes.

At any given stage of precipitation, the small particles will grow at a slower rate than a larger particle because the capillarity effect reduces the supersaturation for small particles. Capillarity has the consequence that large particles have lower solute concentrations at the interface, $c_{r}^{\alpha \beta}$, than small particles. This drives coarsening, which becomes a natural consequence of the precipitation theory, since changes, including the dissolution of particles, continue to happen as long as there are solute concentration gradients.

\section{Calculations}

\subsection{Parameters required for calculations}

$\Delta G_{\mathrm{V}}$, the chemical free energy change per unit volume of precipitate, is given by

$$
\Delta G_{\mathrm{V}}=\frac{\Delta G}{v^{i} \times V^{i \alpha}}
$$

where $v^{i}$ is the molar volume of the $i$ th phase and $\Delta G$ is the molar free energy change of the precipitation reaction. $\Delta G$ can be obtained with a CALPHAD via an explicit equation [21]. There are thermodynamic data for $\mathrm{Nb}(\mathrm{C}, \mathrm{N})$, but unfortunately not for the Laves phase and $\mathrm{M}_{6} \mathrm{C}$ type carbide in multi-component systems of the type considered here. However, solubility products have recently been determined [18] and can be used to estimate $\Delta G$ :

$$
\begin{array}{lc}
\mathrm{Fe}_{2} \mathrm{Nb}: & \log [\mathrm{Nb}]=-\frac{3780.3}{T}+2.4646 \\
\mathrm{Fe}_{3} \mathrm{Nb}_{3} \mathrm{C}: & \log [\mathrm{Nb}][\mathrm{C}]^{3}=-\frac{11613}{T}+5.2178
\end{array}
$$

where the concentrations are in wt $\%$ and $T$ is the absolute temperature (table 3). $\mathrm{M}_{6} \mathrm{C}$ includes $\mathrm{Cr}$ and $\mathrm{Nb}$ (figure 3), so the diffusion of both elements needs to be considered. However, there is much more $\mathrm{Cr}$ than $\mathrm{Nb}$ in this steel and the content of $\mathrm{Cr}$ in $\mathrm{M}_{6} \mathrm{C}$ is less than that of $\mathrm{Nb}$ (figure 3 and table 2). The similar diffusion coefficients of both these elements (Fridberg et al [27]) 
Table 3. Parameters used in the kinetic calculations of $\mathrm{NbN}, \mathrm{Fe}_{2} \mathrm{Nb}$ and $\mathrm{Fe}_{3} \mathrm{Nb}_{3} \mathrm{C}$ precipitation in a $19 \mathrm{Cr}-0.8 \mathrm{Nb}$ wt $\%$ steel and $D_{0}$ in diffusion coefficient and activation energy for diffusion of $\mathrm{Nb}$ and $\mathrm{Cr}$ in ferrite [27]

\begin{tabular}{|c|c|}
\hline \multicolumn{2}{|l|}{ Number density of sites: $N_{0}$} \\
\hline $\mathrm{NbN}\left(\mathrm{m}^{-3}\right)$ & $2 \times 10^{12}$ \\
\hline $\mathrm{Fe}_{2} \mathrm{Nb}\left(\mathrm{m}^{-3}\right)$ & $3 \times 10^{11}$ \\
\hline $\mathrm{Fe}_{3} \mathrm{Nb}_{3} \mathrm{C}\left(\mathrm{m}^{-3}\right)$ & $3 \times 10^{12}$ \\
\hline \multicolumn{2}{|l|}{ Interfacial energy: $\sigma$} \\
\hline $\mathrm{NbN}\left(\mathrm{J} \mathrm{m}^{-2}\right)$ & 0.230 \\
\hline $\mathrm{Fe}_{2} \mathrm{Nb}\left(\mathrm{J} \mathrm{m}^{-2}\right)$ & 0.280 \\
\hline $\mathrm{Fe}_{3} \mathrm{Nb}_{3} \mathrm{C}\left(\mathrm{J} \mathrm{m}^{-2}\right)$ & 0.330 \\
\hline$D_{0}$ in diffusion coefficent of $\mathrm{Nb}$ in ferrite $\left(\mathrm{m}^{2} \mathrm{~s}^{-1}\right)$ & $1.3 \times 10^{-4}$ \\
\hline Activation energy for diffusion of Nb in ferrite: $Q\left(\mathrm{~J} \mathrm{~mol}^{-1}\right)$ & $240 \times 10^{3}$ \\
\hline$D_{0}$ in diffusion coefficent of $\mathrm{Cr}$ in ferrite $\left(\mathrm{m}^{2} \mathrm{~s}^{-1}\right)$ & $1.5 \times 10^{-4}$ \\
\hline Activation energy for diffusion of $\mathrm{Cr}$ in ferrite: $Q\left(\mathrm{~J} \mathrm{~mol}^{-1}\right)$ & $240 \times 10^{3}$ \\
\hline
\end{tabular}

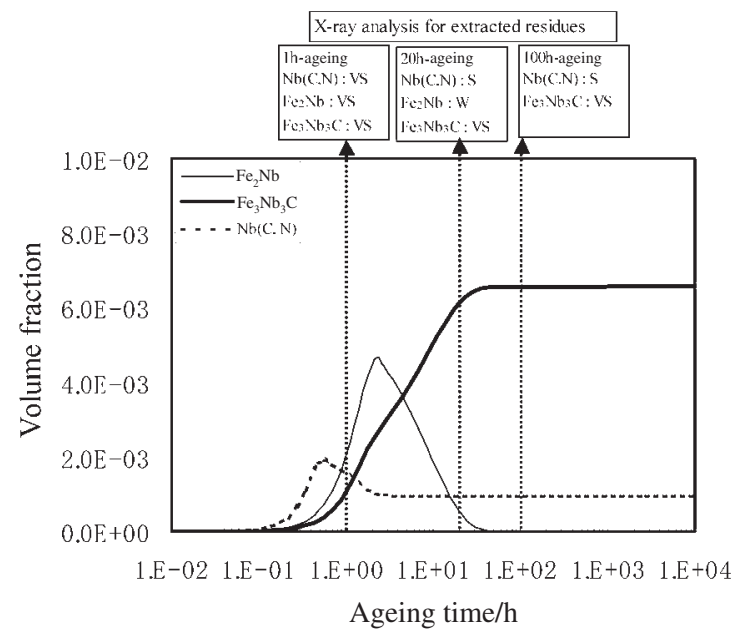

Figure 8. Calculations of multiple precipitation reactions for a $19 \mathrm{Cr}-0.8 \mathrm{Nb}$ wt $\%$ steel aged at $950^{\circ} \mathrm{C}$.

are shown in table 3. Bearing these observations in mind, the calculations have been carried out assuming that the precipitation proceeds in a $\mathrm{Fe}-\mathrm{Nb}-\mathrm{C}$ system. There are two unknown parameters, the number density of nucleation sites $N_{0}$ and the interfacial energy $\sigma$. They are treated as fitting parameters. The sensitivity of the results to these fitting parameters has been in the context of $\mathrm{M}_{6} \mathrm{C}$ precipitation in a niobium-alloyed ferritic stainless steel and that on the $\mathrm{NbC}$ in austenite has been reported $[10,16]$. It is found that the results are affected more by the interfacial energy than the number density. For example, an order of magnitude increase in $N_{0}$ leads to an approximately $20 \%$ decrease in mean particle size and a corresponding increase in $\sigma$ leads to approximately a three fold increase in mean particle size. The parameters in this paper were chosen to obtain a reasonable agreement with experiments.

\subsection{Volume fraction}

Calculated volume fractions for each phase at $950^{\circ} \mathrm{C}$ are shown in figure 8 along with the experimental observations. The model is able to correctly estimate the precipitation sequence. 


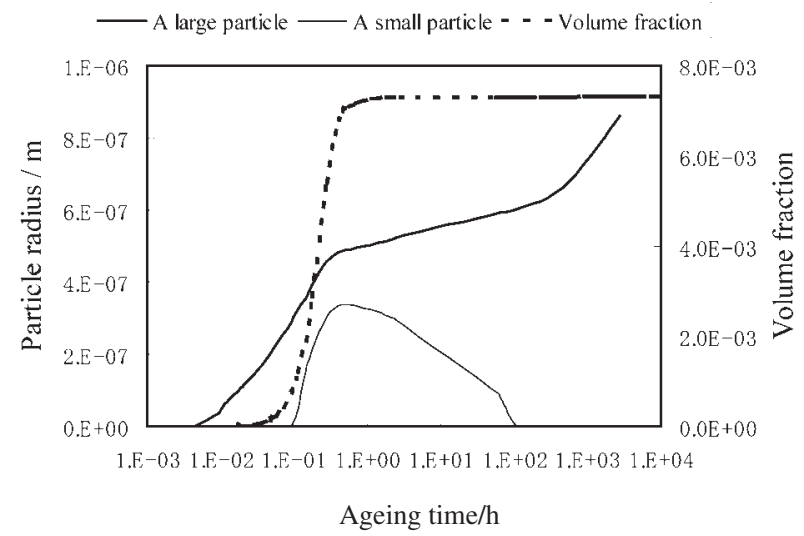

Figure 9. Calculated data on the volume fraction and particle radius changes for $\mathrm{Fe}_{3} \mathrm{Nb}_{3} \mathrm{C}$ at $1000^{\circ} \mathrm{C}$ in a $19 \mathrm{Cr}-0.8 \mathrm{Nb}$ wt $\%$ steel with $N_{0}=3 \times 10^{12} \mathrm{~m}^{-3}$ and $\sigma=0.33 \mathrm{~J} \mathrm{~m}^{-2}$.

\subsection{Particle size}

Figure 9 shows the calculation results indicating how the particle radius and volume fraction of $\mathrm{Fe}_{3} \mathrm{Nb}_{3} \mathrm{C}$ which can be assumed to be an equilibrium phase changes with ageing time at $1000^{\circ} \mathrm{C}$. As expected, a large particle, which nucleated early, grows continuously even as the volume fraction approaches equilibrium. However, because of the capillarity effect, the small particle which nucleated late begins to dissolve even as the large one grows. Figure 10 shows the changes in volume fraction, mean particle radius and number density with ageing time at $1000^{\circ} \mathrm{C}$ and the experimental data of the mean particle radii for $\mathrm{Fe}_{3} \mathrm{Nb}_{3} \mathrm{C}$.

The measured mean radii remain level until $100 \mathrm{~h}$ followed by a gradual increase. As shown in figure 4 , the frequency of large particles increases and that of small particles decreases after $100 \mathrm{~h}$ ageing. After a stasis region where the number density does not change, coarsening occurs, where the mean particle radius tends to change in proportion to $\frac{1}{3}$. This is described as Ostwald ripening [28]. In the stasis region, some particles begin to dissolve, as is also evident from the plots shown in figure 9. However, most of the particles nucleate early so it takes considerable time for the smaller amongst them to dissolve, given that this coarsening phenomenon is driven by small capillarity-induced concentration gradients.

Although the experimental data are not in the parabolic growth stage but in the stasis and coarsening regions, the calculated kinetics compare well with experiments. The calculations represent the whole of the precipitation process from nucleation to coarsening of $\mathrm{Fe}_{3} \mathrm{Nb}_{3} \mathrm{C}$ carbide, which is assumed to be the equilibrium phase. One computational problem with calculations of this kind is that the timescales associated with the precipitation and with the coarsening stages are large. Caution must, therefore, be exercised to avoid the accumulation of numerical errors. The computational time steps were chosen to avoid these difficulties without making the calculation time unbearable. The other reason for discrepancy between calculations and experiments is the interfacial energy. The values must, in principle, change with coherency [9].

\section{Summary}

A methodology has been developed to deal with the nucleation and growth of spherical precipitates of multiple precipitation reactions, $\mathrm{Nb}(\mathrm{C}, \mathrm{N})$, Laves phase and $\mathrm{M}_{6} \mathrm{C}$ in 

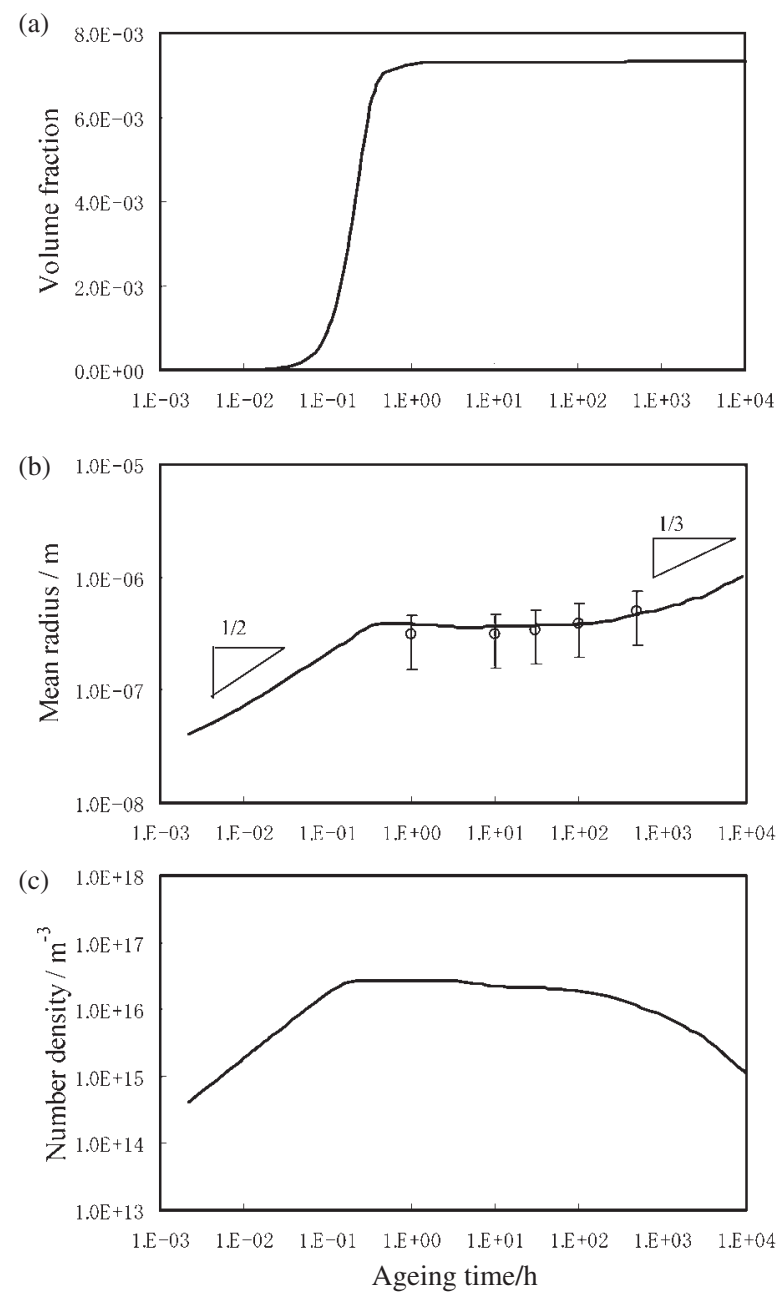

Figure 10. Changes of $(a)$ volume fraction, $(b)$ mean particle size and $(c)$ number density of $\mathrm{Fe}_{3} \mathrm{Nb}_{3} \mathrm{C}$ with ageing time at $1000^{\circ} \mathrm{C}$ for a $19 \mathrm{Cr}-0.8 \mathrm{Nb}$ wt $\%$ steel.

niobium-alloyed ferritic stainless steels of the type used to manufacture automobile exhaust manifolds. The method includes capillarity and so allows the simulation of the whole precipitation process from nucleation to coarsening for an equilibrium phase. Choosing two adjustable parameters, i.e. the number density of nucleation sites and the interfacial energy, the calculations showed good agreement with experimental measurements of both volume fraction and particle size.

\section{References}

[1] Nakamura S, Miyagusu K and Uematsu Y 1991 CAMP-ISIJ 41788

[2] Ohmura K, Fujita N, Kikuchi M, Suzuki T and Hiroshige I 1991 CAMP-ISIJ 41796

[3] Miyazaki A, Gunzi M and Yoshioka K 1993 Kawasaki Steel Giho. 25112

[4] Akiyama S 1991 Nippon Stainless Tech. Rep. 2657

[5] Fujita N, Ohmura K, Kikuchi M, Suzuki T, Funaki S and Hiroshige I 1996 Scr. Mater. 35705 
[6] Dutta B and Sellars M 1987 Mater. Sci. Technol. 3197

[7] Saito Y, Shiga C and Enami T 1988 Proc. Int. Conf. on Physical Metallurgy of Thermomechanical Processing of Steels and Other Metals ed I Tamura (Tokyo: ISIJ) p 753

[8] Akamatsu S, Matsumura Y, Senuma T, Yada H and Ishikawa S 1989 Tetsu-to-Hagane 75933

[9] Okamoto R and Suehiro M 1998 Tetsu-to-Hagane 84650

[10] Fujita N and Bhadeshia H K D H 2001 Mater. Sci. Technol. 17403

[11] Baker R G and Nutting J 1959 J. Iron Steel Inst. 192257

[12] Thomson R C and Bhadeshia H K D H 1994 Mater. Sci. Technol. 10193

[13] Robson J D and Bhadeshia H K D H 1997 Mater. Sci. Technol. 13631

[14] Fujita N and Bhadeshia H K D H 2002 ISIJ Int. 42760

[15] Robson J D and Bhadeshia H K D H 1996 CALPHAD 20447

[16] Fujita N, Bhadeshia H K D H and Kikuchi M 2002 Metall. Mater. Trans A 333339

[17] Ashby M F and Ebeking R 1966 Trans. TMS-AIME 2361396

[18] Fujita N, Kikuchi M and Ohmura K 2003 ISIJ Int. 431999 accepted

[19] Turnbull D and Fisher J C 1949 J. Chem. Phys. 1771

[20] Russell K C 1968 Phase transformations ASM Seminar p 219

[21] Russell K C 1980 Adv. Colloid Interface Sci. 13205

[22] Christian J W 2001 Theory of Transformations in Metals and Alloys 3rd edn (part 1) (Oxford: Pergamon)

[23] Coates D E 1973 Metall. Trans. A 42313

[24] Kirkaldy J S 1958 Can. J. Phys. 36907

[25] Bhadeshia H K D H 1985 Prog. Mater. Sci. 29321

[26] Zener C 1949 J. Appl. Phys. 20950

[27] Fridberg J, Torndahl L-E and Hillert M 1969 Jernkotorets Ann. 153263

[28] Lifshitz I M and Slyozov V V 1961 J. Phys. Chem. Solids 1935 